PACS: 01.30. $-\mathrm{y}, 04.30 .-\mathrm{w}$

\title{
INCOMMENSURATE CRYSTALLIZATION OF NEUTRON MATTER IN NEUTRON STARS
}

\author{
(D)Kapil M. Khanna*, (D)David K. Kandie, DJoel K. Tonui, (D)Hezekiah K. Cherop \\ Department of Physics, University of Eldoret \\ P.O. Box 1125-30100, Eldoret, Kenya \\ *Corresponding Author: Khannak700@gmail.com
}

Received October 12, 2019; revised January 13, 2020; accepted March 20, 2020

The composition of the neutron stars from its surface region, outer-core, inner-core, and to its center is still being investigated. One can only surmise on the properties of neutron stars from the spectroscopic data that may be available from time to time. A few models have suggested that the matter at the surface region of the neutron star is composed of atomic nuclei that get crushed under extremely large pressure and gravitational stress, and this leads to the creation of solid lattice with a sea of electrons, and perhaps some protons, flowing through the gaps between them. Nuclei with high mass numbers, such as ferrous, gold, platinum, uranium, may exist in the surface region or in the outer-core region. It is found that the structure of the neutron star changes very much as one goes from the surface to the core of the neutron star. The surface region is extremely hard and very smooth. Surface irregularities are hardly of the order of $5 \mathrm{~mm}$, whereas the interior of the neutron star may be superfluid and composed of neutron-degenerate matter. However, the neutron star is highly compact crystalline systems, and in terrestrial materials under pressure, many examples of incommensurate phase transitions have been discovered. Consequently, the properties of incommensurate crystalline neutron star have been studied. The composition of the neutron stars in the super dense state remains uncertain in the core of the neutron star. One model describes the core as superfluid neutron-degenerate matter, mostly, composed of neutrons $(90 \%)$, and a small percentage of protons and electrons $(10 \%)$. More exotic forms of matter are possible, including degenerate strange matter. It could also be incommensurate crystalline neutron matter that could be BCC or HCP. Using principles of quantum statistical mechanics, the specific heat and entropy of the incommensurate crystalline neutron star has been calculated assuming that the temperature of the star may vary between $10^{6} \mathrm{~K}$ to $10^{12} \mathrm{~K}$. Two values for the temperature $\mathrm{T}$ that have been arbitrarily chosen for which the calculations have been done are $1.7 \times 10^{6} \mathrm{~K}$ and $1.7 \times 10^{10} \mathrm{~K}$. The values of specific heat and entropy decrease as the temperature increases, and also, their magnitudes are very small. This is in line with the second law of thermodynamics.

KEYWORDS: terrestrial materials, incommensurate phase, incommensurate crystalline neutron star, superfluid, neutron-degenerate matter

An incommensurate quantum solid or crystalline solid is one that need not to have an integer number of atoms per unit cell [1]. For an HCP (Hexagonal Close Packed) lattice of volume V and lattice constant " $a$ ", the number of lattice sites $N_{s}$ is written as,

$$
N_{S}=V \frac{\sqrt{2}}{a^{3}}
$$

If in the ground state the crystal is incommensurate, then its number $N$ of atoms differs from its number of sites $N_{s}$ such that $N \neq N_{s}$. To know how incommensurate the ground state actually is for the quantum solid, it is essential to know or measure the density and lattice constant " $a$ " precisely and simultaneously. If the incommensurability is denoted by $\varepsilon$, then it is defined as,

$$
\varepsilon=\frac{N_{S}-N}{N_{S}}, \quad\left(N_{s}>N\right)
$$

The quantity $\varepsilon$ is defined as the net fractional vacancy number. If $\varepsilon_{0}$ is the value of $\varepsilon$ at absolute zero temperature, and $\delta$ is the change in the incommensurability away from its ground state value $\left(\varepsilon_{0}\right)$, then,

$$
\varepsilon=\varepsilon_{0}+\delta
$$

Staying at $T=0$, the incommensurability is changed away from its ground state value $\left(\varepsilon_{0}\right)$ by changing the number of lattice sites and consequently changes in lattice constant " $a$ ". Thus, if $E_{0}$ is the ground state energy, then $E$ may be the harmonic increase in the crystal energy, when the crystal temperature stays at $T=0$. At the ground state, $\left(\varepsilon_{0}\right), \delta=0$, since $\varepsilon=\varepsilon_{0}$.

If however, the ground state of the crystalline state is commensurate, then there will be exactly one atom per lattice site $\left(N=N_{S}\right)$, and hence $\varepsilon=0$. In fact, the value of $\varepsilon$ depends on the magnitude of the difference between the 
number of atoms $(N)$ and the number of sites $\left(N_{s}\right)$. It is well known that in the ground state of solid ${ }_{2}^{4} H e$, the difference in $N$ and $N_{s}$ is around $1 \%$, whereas in the neutron stars it could be as much as $10 \%$ since in the crystalline state of the neutron stars, there could be roughly $10 \%$ protons and electrons, and the rest $90 \%$ could be neutrons. The structure of crystalline solids is based on a periodic repetition of a certain basic arrangement of atoms. In many solids or materials, this basic arrangement shows vibrations, which are also periodically repeated. If the periodicities of the repetition of the basic (structure) arrangement and that of the variation of this arrangement are commensurate, a super structure results. However, if there do exist solids where the periodicity of the repetition of the basic arrangement and that of its variations are not commensurate, in that case one gets an incommensurate or modulated structure $[2,3,4 \mathrm{a}$, 4b].

Neutron stars have overall densities of $3.7 \times 10^{17} \mathrm{kgm}^{-3}$ to $5.9 \times 10^{17} \mathrm{kgm}^{-3}$ which means $2.6 \times 10^{14}$ to $4.1 \times 10^{14}$ times the density of the Sun [5]. The density of $3.7 \times 10^{17} \mathrm{kgm}^{-3}$ derives from mass $2.68 \times 10^{30} \mathrm{~kg} /$ volume of star of radius $12 \mathrm{~km}$ and $5.9 \times 10^{17} \mathrm{kgm}^{-3}$ is derived from mass $4.2 \times 10^{30} \mathrm{~kg} /$ volume of star of radius $11.9 \mathrm{~km}$. These densities are comparable to the approximate density of an atomic nucleus which is of the order of $3 \times 10^{17} \mathrm{kgm}^{-3}$. The neutrons star's density varies roughly from $1 \times 10^{9} \mathrm{kgm}^{-3}$ in the crust, then increases with depth to about $6 \times 10^{17}$ or $8 \times 10^{17} \mathrm{kgm}^{-3}$ (denser than the atomic nucleus) deeper inside the neutron star (the core of the neutron star) [6].

In terrestrial materials under pressure, many examples of incommensurate phase transitions have been discovered [4a]. Hence, we decided to study the properties of an incommensurate crystalline neutron star. It is still not known exactly whether the crystalline structure is BCC or HCP, and whether it is in the crust or interior (core) or both. However, it will be easier to study experimentally the neutron star crusts as compared to the study of the core or interior of the neutron star.

In neutron stars, which are very high density systems, an essential new concept will be the Fermi energy $E_{F}$. The quantum mechanical way to think about it is in terms of the uncertainty principle [7], which is expressed as,

$$
\Delta x \Delta p=\hbar
$$

and thus in a dense system, like the neutron star, there is a finite momentum, and hence there is the definite energy associated with the confinement. Therefore, squeezing the neutron star increases its total energy, and hence the Fermi energy $\mathrm{E}_{\mathrm{F}}$ acts as the pressure - called the degeneracy pressure. Now at the densities of neutron star, i.e., $\rho>6 \times 10^{15} \mathrm{gcm}^{-3}$ or so, the electrons are highly relativistic, whereas the neutrons and protons are $\left(m_{N} \cong m_{P} \cong 1837 m_{e}\right)$ slightly less relativistic since these are heavy particles when compared to the electrons. At very high densities, the neutron star has a smooth distribution of neutrons, plus a $5-10 \%$ smattering of protons and electrons. Since the number of neutrons is comparatively very large, the neutron Fermi energy could become very high enough such that the other particles like protons and electrons could appear as separate entities. The composition of the super dense neutron star remains uncertain in the core of the neutron star. One model describes the core as superfluid neutron - degenerate matter, mostly composed of neutrons, and a small percentage $(10 \%)$ of protons and electrons. More exotic forms of matter are possible, including degenerate strange matter [8a]. In the crystalline state, the neutron star is assumed to be composed of some $90 \%$ neutrons, and $10 \%$ protons. It is also surmised that when the temperature of the neutron star is $T=100 \mathrm{KeV}=11.5942 \times 10^{8} \mathrm{~K}$, the proton fraction $\left(F_{p}\right)$ could have different values at different densities of the neutron star. It is proposed that $F_{p}$ increases as the density $\rho$ of the neutron star increases [8a]. This means that the neutron star in such a crystalline state is incommensurate, and this means that the number of sites $\left(N_{s}\right)$ for the neutrons is more than the number of neutrons $(N)$.If the number of neutrons is $90 \%$, then $10 \%$ of the sites will be occupied by the protons. The incommensurability for neutrons and protons will be given by Eq.(2). Keeping this in mind, a theory is developed for the incommensurate neutron star, and its thermodynamic properties, especially specific heat $\left(C_{v}\right)$ and entropy $(S)$ are calculated.

\section{SIGNIFICANCE OF THE RESEARCH WORK}

Although several equations of state have been proposed, the exact equation of state for neutron star is still not known. Similarly, the exact composition of the neutron star from its surface region to the core is still not known. Some models indicate that the matter at the surface of the neutron star is composed of ordinary atomic nuclei crushed into a solid lattice with a sea of electrons flowing through the gaps between them, and there could also be some protons. Nuclei with very high binding fraction such as iron could exist in the surface region. The structure of the neutron star varies drastically and characteristically from the extremely hard and very smooth (with maximum surface irregularities of approximately $5 \mathrm{~mm}$ ) surface to the inner crystalline crust and core of the neutron star. Proceeding inwards, one can encounter superfluid neutron-degenerate matter, mostly composed of neutrons, some protons and electrons. Although 
the inner crust and core have very high temperatures, of order of $10^{7} \mathrm{~K}$ to $10^{10} \mathrm{~K}$; extremely high density results in extremely high gravitational field or stress, and extremely high pressure; and all put together can result in a crystalline structure of the neutron star with $90 \%$ neutrons and $10 \%$ protons. It is also not known exactly whether the outer crust and the inner crust are $\mathrm{BCC}$ or $\mathrm{HCP}$ and there are suggestions that the proton fraction could be more than $10 \%$. Since the neutron star assumed to be composed of $90 \%$ of neutrons, $10 \%$ protons, is very compact, has very large density, has very large or extremely large gravitational stress and pressure; it can be safely assumed that it may be an incommensurate crystalline structure. It was therefore decided that, the crystalline state of a neutron star with $90 \%$ neutrons and $10 \%$ protons be studied to understand some thermodynamic properties of the neutron star, such as specific heat and entropy. A crystalline structure of this type is called incommensurate, and in this, the number of sites and the number of occupants of the sites are not equal, rather, the number of sites is more than the number of occupants [6, 8a, $8 \mathrm{~b}, 8 \mathrm{c}, 8 \mathrm{~d}]$.

The theory of quantum statistical mechanics; the method of calculating the activation energy of vacancy formation in crystalline neutron star, have been used to study the problem and the principles of thermodynamics have been used to calculate the specific heat $\left(C_{v}\right)$, and the entropy $(S)$, of the incommensurate crystalline state of the neutron star.

\section{THE THEORY OF INCOMMENSURATE CRYSTALLINE NEUTRON STAR}

A neutron star's almost incompressible structure results in very large density, even more than nuclear density, and this causes protons and electrons to combine into neutrons, the process that gives such stars their name. The composition of the cores of the neutron stars is still not exactly known, but they may consist of a neutron superfluid or some unknown state of matter, or have some crystalline structure $[9,10 \mathrm{a}, 10 \mathrm{~b}]$.

It is possible that not all the neutrons may become part of the crystalline state of a neutron star. There may be some free neutrons whose lifetime may be about 15 minutes, and they can decay as,

$$
n \rightarrow p+e^{-}+V_{e}
$$

where, $n=$ neutron, $p=$ proton, $e^{-}=$electron or $\beta$-particle and $V_{e}=$ neutrino associated with negative electron emission.

This shows that due to the $\beta$ - decay, there will be electrons and protons in addition to the neutrons in the neutron star. The electron number density and the proton number density are small compared to the neutron number density [11]. The maximum number density of the protons cannot be more than $1 / 8$ of the total number of density in the neutron star [12]. Thus, it can be assumed that the crystalline state of a neutron star is incommensurate, i.e., the number of sites $N_{s}$ is not equals to the number of neutrons, and that $N_{S}>N$.

It is to be emphasized that in terrestrial materials under pressure, many examples of in-commensurate phase transitions have been discovered [13]. Information so far indicates the existence of BCC structure in the crust of the neutron star. It is still not exactly known whether in the interior of the neutron star, the structure is BCC or HCP. However, it is easier to study experimentally the neutron star crust compared to the interior of the neutron star [14]. It seems quite certain that both the crust and the interior of the neutron star are in the crystalline state such that there may be $90 \%$ neutrons and $10 \%$ protons that may occupy the crystal sites, and hence the neutron star will be in the incommensurate crystalline state. Hence, we consider a crystalline system composed of $90 \%$ neutrons and $10 \%$ protons. For the lattice system for protons, only 10 out of 100 lattice sites will be occupied, the rest will be empty. Similarly for the lattice system for neutrons, 90 out of 100 lattice sites will be occupied, the rest will be empty. However, in the crystalline state, the difference between the neutrons and protons will be assumed to disappear, and even if they are at the same lattice site, they can co-exist on the same lattice site without disturbing each other or the rest of the system, or the particles on the rest of the lattice sites.

It is well known that in the crystalline state or a quantum solid, the system is intrinsically restless, and the energy it possesses is the zero-point energy that is calculated using the Heisenberg's Uncertainty principle $[15,16]$. In this manuscript, the crystalline state is assumed to be incommensurate such that the number of neutrons $N_{n}$ is less than the number of sites $\left(N_{s}\right)$ and also the number of protons $\left(N_{p}\right)$ is less than $N_{s}$. Thus the ground state of the quantum state is incommensurate such that $N_{n}<N_{s}$ and $N_{p}<N_{s}$. The energy of such a system is calculated in this manuscript using the principles of quantum statistical mechanics.

Now we will write the incommensurability constant, $\varepsilon_{p}$ for protons as,

$$
\varepsilon_{p}=\frac{N_{s}-N_{p}}{N_{s}}
$$

and the incommensurability constant, $\varepsilon_{n}$, for neutrons as, 


$$
\varepsilon_{n}=\frac{N_{s}-N_{n}}{N_{s}}
$$

By definition $\varepsilon_{p}$ and $\varepsilon_{n} \neq 1$, they are both less than $1\left(\varepsilon_{p}<1, \varepsilon_{n}<1\right)$. It is also assumed that there is no disorder (in the crystalline state) and no inter site interaction in the crystalline state. This would mean that the particles and sites can be freely permuted. The number of ways we can permute particles and sites will then be $\left(N_{s}+N_{p}+N_{n}\right)$ !. Since in the crystalline state, the distinction between protons and neutrons is lost, permutation among them must be excluded by dividing by $\left(N_{p}+N_{n}\right)$ !.

Similarly, the permutations among identical sites must also be excluded by dividing by $N_{s}$ !. Thus the number of ways in which neutrons and protons can be distributed among the sites is given by $P$, such that,

$$
P=\frac{\left(N_{s}+N_{p}+N_{n}\right)}{\left(N_{s}\right)\left(N_{p}+N_{n}\right) !}
$$

Hence the statistical count, $\mathrm{C}$, for the incommensurability of neutrons and protons in the crystalline neutron matter in a neutron star is,

$$
P=\prod_{S} \frac{\left(N_{s}+N_{p}+N_{n}\right)}{\left(N_{s} !\right)\left(N_{p}+N_{n}\right) !}
$$

Taking logarithms of both the sides, we can write,

$$
\begin{gathered}
\log C=\log \prod_{S} P=\log \prod_{S} \frac{\left(N_{s}+N_{p}+N_{n}\right) !}{\left(N_{s} !\right)\left(N_{p}+N_{n}\right) !} \\
=\sum_{s}\left[\log \left(N_{s}+N_{p}+N_{n}\right) !-\log N_{s} !-\log \left(N_{p}+N_{n}\right) !\right]
\end{gathered}
$$

For large $N$, Stirling's theorem gives,

$$
\log N !=N \log N-N
$$

Using Eq. (11) in Eq. (10) and simplifying, we get,

$$
\log C=\sum_{s}\left[\left(N_{s}+N_{p}+N_{n}\right) \log \left(N_{s}+N_{p}+N_{n}\right)-N_{s} \log N_{s}-\left(N_{p}+N_{n}\right) \log \left(N_{p}+N_{n}\right)\right]
$$

Now we assume that $N_{s}$ is uniquely determined for a given crystalline structure, and in that case, it will have only one value. We denote this by $\eta_{0}$ such that, $\eta_{0}=N_{S}$, although we will continue with the notation $N_{s}$ for the number of sites. Hence, the summation over $S$ in Eq. (12) will have only one value on the right hand side, and we get,

$$
\log C=\left(N_{s}+N_{p}+N_{n}\right) \log \left(N_{s}+N_{p}+N_{n}\right)-N_{s} \log N_{s}-\left(N_{p}+N_{n}\right) \log \left(N_{p}+N_{n}\right)
$$

Now from Eq. (6), we can write,

$$
N_{s}=\frac{N_{p}}{1-\varepsilon_{p}}
$$

In addition, from Eq. (7), we can write,

$$
N_{s}=\frac{N_{n}}{1-\varepsilon_{n}}
$$

Combining Eqs. (14) and (15), we can write, for $N_{s}$, 


$$
N_{s}=\frac{\left(N_{p} N_{n}\right)^{1 / 2}}{\left[\left(1-\varepsilon_{p}\right)\left(1-\varepsilon_{n}\right)\right]^{1 / 2}}
$$

Using Eqs. (14) and (15), we can write the values of $\left(N_{s}+N_{p}+N_{n}\right)$ and $\left(N_{p}+N_{n}\right)$ in Eq. (13), i.e.,

$$
N_{s}+N_{p}+N_{n}=N_{s}+N_{s}\left(1-\varepsilon_{p}\right)+N_{s}\left(1-\varepsilon_{n}\right)=N_{s}\left(3-\varepsilon_{p}-\varepsilon_{n}\right)
$$

and

$$
N_{p}+N_{n}=N_{s}\left(1-\varepsilon_{p}\right)+N_{s}\left(1-\varepsilon_{n}\right)=N_{s}\left(2-\varepsilon_{p}-\varepsilon_{n}\right)
$$

Substituting Eqs. (17) and (18) in Eq. (13) gives,

$$
\log C=N_{s}\left\{\left(3-\varepsilon_{p}-\varepsilon_{n}\right)\left\{\log N_{s}+\log \left(3-\varepsilon_{p}-\varepsilon_{n}\right)\right\}-\log N_{s}-\left(2-\varepsilon_{p}-\varepsilon_{n}\right)\left\{\log N_{s}+\log \left(2-\varepsilon_{p}-\varepsilon_{n}\right)\right\}\right\}
$$

Re-arranging terms in $\log N_{s}$ and the other terms gives,

$$
\log C=N_{s}\left\{\left(3-\varepsilon_{p}-\varepsilon_{n}\right) \log \left(3-\varepsilon_{p}-\varepsilon_{n}\right)-\left(2-\varepsilon_{p}-\varepsilon_{n}\right) \times \log \left(2-\varepsilon_{p}-\varepsilon_{n}\right)\right\}
$$

Eq. (20) will be used to calculate the thermodynamic properties, especially specific heat $C_{v}$ and the entropy $\mathrm{S}$ of an incommensurate neutron star. Thus we have to fix the values of the incommensurability constants $\varepsilon_{p}$ and $\varepsilon_{n}$.

In general, a neutron star is divided into many regions. The outer crust is supposed to be solid, and has nuclei and electrons. The inner crust is assumed to be solid-superfluid and composed of nuclei, neutrons and electrons; the outer core is supposed to be superfluid - superconductor and composed of neutrons, protons and electrons; the constitution of the inner core is still uncertain $[17,18,19,20,21,22,23,24,25]$.The density of each region of the star also varies. Depending upon the types of excitations, the specific heat expression also changes. In another calculation the specific heat was also calculated in the different baryonic density conditions corresponding to the inner crust and in the temperature range $100 \mathrm{KeV} \quad\left(T=11.5942 \times 10^{8} \mathrm{~K}\right)$ to $2 \mathrm{MeV}\left(T=2.3188 \times 10^{10} \mathrm{~K}\right)$. Different values for the proton fraction against total baryonic density were obtained at $T=100 \mathrm{KeV}[26,27,28,29]$. However, we have assumed that in the incommensurate crystalline state of the neutron star, the number of neutrons is $90 \%$, and the number of protons is $10 \%$, and this will determine the values of $\varepsilon_{n}$ and $\varepsilon_{p}$.

Now in the case of incommensurate quantum solid, vacancies can occur such that the number of particles that occupy the sites is less than the number of sites. In general, vacancies occur naturally in all crystalline materials. At any given temperature, up to the melting point of the material, there is what is called equilibrium concentration (ratio of vacant sites to those containing atoms $[15,16]$, is also called vacancy concentration). At the melting point of some metals, this ratio can be roughly 1:1000. Now the temperature dependence of the vacancy concentration, $N_{v}$, can be modeled by,

$$
N_{V}=N_{S}\left(e^{-\frac{Q_{V}}{k T}}\right)
$$

where, $Q_{V}$ - energy required for vacancy formation, $k$ - Boltzmann constant, $T$ - Absolute temperature, $N_{S}$ concentration of atomic sites.

Here $N_{S}$ is given by,

$$
N_{S}=\frac{\rho N_{A}}{A}
$$

where $\rho$ - density, $A$ - atomic mass, and $N_{A}$ - Avogadro's number.

Vacancies are formed during solidification due to vibrations of atoms, plastic deformation, BCC and HCP.

To make the calculations more explicit, we write,

$$
\begin{aligned}
& N_{V}=\text { vacancy concentration, } \\
& N_{S}=\text { number of sites } \\
& N_{p}=\text { number of protons } \\
& N_{n}=\text { number of neutrons }
\end{aligned}
$$


Now for protons, vacancy concentration, $v_{p}$, is the ratio of vacant lattice sites to those containing protons [27] i.e.,

$$
v_{p}=\frac{N_{s}-N_{p}}{N_{p}} .
$$

Similarly, the vacancy concentration, $v_{n}$, for the neutrons is the ratio of vacant lattice sites to those containing neutrons [17], i.e.,

$$
v_{n}=\frac{N_{s}-N_{n}}{N_{n}}
$$

Now if $Q_{p}$ is the energy required for proton vacancy formation, and $Q_{n}$ is the energy required for neutron vacancy formation, then from Eq. (21), we can write,

$$
\begin{aligned}
& v_{p}=\frac{N_{s}-N_{p}}{N_{p}}=N_{s} e^{-\left(\frac{Q_{p}}{k T}\right)} \\
& v_{n}=\frac{N_{s}-N_{n}}{N_{n}}=N_{s} e^{-\left(\frac{Q_{n}}{k T}\right)}
\end{aligned}
$$

Combining Eqs. (25) and (26), we can write,

$$
N_{s}=\left(v_{p} v_{n}\right)^{\frac{1}{2}} e^{\left(\frac{Q_{p}+Q_{n}}{k T}\right)}
$$

Substituting for $N_{s}$ from Eq. (27) in Eq. (20), gives,

$$
\log C=\left[\left(3-\varepsilon_{p}-\varepsilon_{n}\right) \log \left(3-\varepsilon_{p}-\varepsilon_{n}\right)-\left(2-\varepsilon_{p}-\varepsilon_{n}\right) \times \log \left(2-\varepsilon_{p}-\varepsilon_{n}\right)\right]\left(v_{p} v_{n}\right)^{\frac{1}{2}} e^{\left(\frac{Q_{p}+Q_{n}}{2 k T}\right)}
$$

Eq. (28) depends on the essential parameters of the incommensurate crystalline state of the neutron star in such a way that the $N_{s}$ is eliminated. Now we can write,

$$
\log C=[A-B]\left(v_{p} v_{n}\right)^{1 / 2} e^{\left(\frac{Q_{n}+Q_{n}}{k T}\right)}
$$

where,

$$
\begin{aligned}
& A=\left(3-\varepsilon_{p}-\varepsilon_{n}\right) \log \left(3-\varepsilon_{p}-\varepsilon_{n}\right) \\
& B=\left(2-\varepsilon_{p}-\varepsilon_{n}\right) \log \left(2-\varepsilon_{p}-\varepsilon_{n}\right)
\end{aligned}
$$

The Gibb's free energy of the incommensurate crystalline neutron star can be written as, $G$, i.e.,

$$
G=-\int k \log C d T
$$

Substituting for $\log C$ from Eq. (29) into Eq. (32) and integrating gives, $G$ as,

where,

$$
\begin{gathered}
G=2 k^{2}[A-B]\left(v_{p} v_{n}\right)^{1 / 2}\left(\frac{T^{2}}{Q_{p}+Q_{n}}\right) e^{\left(\frac{Q_{p}+Q_{n}}{2 k T}\right)} \\
G=\eta T^{2} e^{\left(\frac{Q_{p}+Q_{n}}{2 k T}\right)}
\end{gathered}
$$

$$
\eta=2 k^{2}[A-B]\left(v_{p} v_{n}\right)^{1 / 2}\left(\frac{1}{Q_{p}+Q_{n}}\right)
$$


The entropy, $S$, of the system is given by,

\section{THE ENTROPY (S)}

$$
\begin{gathered}
S=-\left(\frac{\partial G}{\partial T}\right) \\
S=\eta\left(\frac{Q_{p}+Q_{n}}{2 k}-2 T\right) e^{\left(\frac{Q_{p}+Q_{n}}{2 k T}\right)}
\end{gathered}
$$

Eq. (37) is obtained by substituting the value of $G$ from Eq. (34) in Eq.(36).

The specific heat $C_{v}$ is given by,

\section{THE SPECIFIC HEAT $\left(\mathrm{C}_{\mathrm{V}}\right)$}

$$
C_{v}=T\left(\frac{\partial S}{\partial T}\right)
$$

Substituting the value of S in Eq. (38) from Eq. (37), we obtain,

$$
C_{v}=-\eta\left(\frac{Q_{p}+Q_{n}}{2 k}\right)^{2}\left(\frac{1}{T}\right) e^{\left(\frac{Q_{p}+Q_{n}}{2 k T}\right)}-2 \eta T e^{\left(\frac{Q_{p}+Q_{n}}{2 k T}\right)}+2 \eta\left(\frac{Q_{p}+Q_{n}}{2 k}\right) e^{\left(\frac{Q_{p}+Q_{n}}{2 k T}\right)}
$$

\section{CALCULATION OF THE ACTIVATION ENERGY OF VACANCY FORMATION IN CRYSTALLINE NEUTRON STAR}

In the incommensurate crystalline neutron star, there will be activation energy $\left(Q_{n}\right)$ for vacancy formation for neutrons and the activation energy $\left(Q_{p}\right)$ for vacancy formation for protons. From Eq. (26), the vacancy formation activation energy, $Q_{n}$, for neutrons can be written as,

$$
Q_{n}=-k T \log \frac{v_{n}}{N_{s}}
$$

Similarly the activation energy, $Q_{p}$, for the vacancy formation for protons can be written from Eq.(25) as,

$$
Q_{p}=-k T \log \frac{v_{p}}{N_{s}}
$$

Thus in the crystalline neutron star in which $90 \%$ of the sites are assumed to be occupied by the neutrons, and $10 \%$ are occupied by protons, $v_{n}=1 / 9$ and $v_{p}=9$. Now, to get the values of the entropy $S$ and specific heat $C_{v}$, we have to calculate the values of $Q_{n}$ and $Q_{p}$ from Eqs. (40) and (41), and to get the values of $Q_{n}$ and $Q_{p}$, we need the value of $N_{s}$ that is obtained from Eq.(22). To know the value of $N_{s}$, we need to know the value of the density $\rho$ of the neutron star, and this is assumed to be,

$$
\rho=3.7 \times 10^{17} \mathrm{~kg} / \mathrm{m}^{3} \text { to } 5.9 \times 10^{17} \mathrm{~kg} / \mathrm{m}^{3}
$$

Now we have to calculate the activation energy for vacancy formation by first calculating the number of sites $N_{s}$ given by Eq. (22). The general expression for the activation energy, $Q_{v}$, for vacancy formation is given by,

$$
Q_{v}=-k T \log \left(\frac{N_{v}}{N}\right)=k T \log \left(\frac{N}{N_{v}}\right)
$$

Knowing the temperature $T$ of the star, $Q_{v}$ can be calculated by knowing $N_{v}$ which is the equilibrium number of vacancies at the temperature of the star. Thus, for neutron star with $90 \%$ neutrons, the vacancies at equilibrium will be $10 \%$, and for on-site protons, which are $10 \%$, the vacancies at equilibrium will be $90 \%$. Hence for neutrons on-site, $N_{v}^{n}=\frac{10 N}{100}=\frac{N}{10}$, and for protons on-site, $N_{v}^{p}=\frac{90}{100} N=\frac{9}{10} N$. Now we can calculate $Q_{v}^{n}$ for neutrons on-site, and $Q_{v}^{p}$ for protons on-site. Using Eq. (43) we get, for $T=10^{6} \mathrm{~K}$,

$$
Q_{v}^{n}=k T \log 10=2.3 k T=198.375 \mathrm{eV}
$$


Similarly, we can write for $Q_{v}^{p}$ as,

$$
Q_{v}^{p}=k T \log \frac{10}{9}=k T[2.30-2.19]=0.11 \mathrm{kT}=24.30 \mathrm{eV}
$$

Eq. (44) gives the activation energy for the vacancy formation in the case of neutrons, and Eq. (45) gives the activation energy for vacancy formation in the case of protons when the temperature of the neutron star is $T \approx 10^{6} \mathrm{~K}$. However, in literature different values for the temperature, $T$, of neutron stars are given. For instance in one calculation [26], $T$ Variation is taken as $T=100 \mathrm{KeV}=11.5942 \times 10^{8} \mathrm{~K}$ to $T=2 \mathrm{MeV}=2.3188 \times 10^{10} \mathrm{~K}$, and the specific heat was calculated for the inner crust of the neutron star. They also calculated the variation of the proton fraction with baryonic gas density at $T=100 \mathrm{KeV}$. Since there are large variations in the density, composition and temperature of the neutron star as we go from the core to the crust, all the values of different physical parameters will be approximate or speculative. In general thermodynamic calculations of the inner crust neglect temperature variation of the proton fraction since the chemical potentials of neutron $\left(\mu_{n}\right)$, proton $\left(\mu_{p}\right)$ and electron $\left(\mu_{e}\right)$ depend on the temperature via an equilibrium condition [27],

$$
\mu_{n}(T)-\mu_{p}(T)=\mu_{e}(T)
$$

Thus in our calculations, we have assumed that $N_{v}^{n}$ and $N_{v}^{p}$ will remain constant even if the value of $T$ changes, and the value of $Q_{v}^{n}$ and $Q_{v}^{p}$ given in Eqns. (44) and (45) will be used to calculate the values of entropy $S$ and specific heat $C_{v}$ for different values of $T$ that may vary between $10^{6} \mathrm{~K}$ to $10^{12} \mathrm{~K}$.

\section{CALCULATION OF ENTROPY (S)}

In physics, entropy is defined as a mathematical function that describes the thermodynamic macro state of a physical system constituted from the statistical description of the system. Entropy describes the thermodynamic evolution of the system in time, and hence entropy plays a key role in any process in Universe, and this is particularly so in astrophysical objects in nature such as stars, neutron stars etc. Same is true of the specific heat since both specific heat and entropy are related to each other via a fundamental thermodynamic relation

$$
T d S=d u+p d v
$$

The expression for entropy, $S$, is given by Eq. (37). In the expression for entropy, the values of $Q_{v}^{n}$ and $Q_{v}^{p}$ (or $Q_{n}$ and $Q_{p}$ ) are given by the Eqns. (44) and (45). We have to calculate the value of $\eta$, which is given by Eq. (35). For $\varepsilon_{n}=\frac{1}{10}$ and $\varepsilon_{p}=\frac{9}{10}$, and $v_{p}=9$ and $v_{n}=\frac{1}{9}$. The value of $\eta$ will be written as,

$$
\eta=2 k^{2}(1.386)\left(\frac{1}{198.375 e V+24.3 e V}\right)
$$

Thus the expression for entropy, $S$, is,

$$
S=\frac{1.9125}{T} \times 10^{-16} \operatorname{erg}\left(e^{\frac{1.7 \times 10^{6}}{T}}\right)
$$

Now if we arbitrarily decide that the temperature $T$ of the neutron star is $1.7 \times 10^{6} \mathrm{~K}$, and this is being done for convenience of calculation ( $T$ can vary from $10^{6} \mathrm{~K}$ to $10^{12} \mathrm{~K}$ ), we get,

$$
S=2.4435 \times 10^{-22} \mathrm{erg} / \mathrm{K}
$$

We can go on increasing the value of $T$ as, $2 \times 1.7 \times 10^{6} \mathrm{~K}, 3 \times 1.7 \times 10^{6} \mathrm{~K}$, and so on to $10^{4} \times 1.7 \times 10^{6} \mathrm{~K}$ and we find that $\left(e^{\frac{1.7 \times 10^{6}}{T}}\right)$ keeps decreasing such that for $T=10^{4} \times 1.7 \times 10^{6} \mathrm{~K}$ its value will be roughly 1.00007757 , which can be approximated as unity. Hence, for $T=1.7 \times 10^{10} \mathrm{~K}$, the value of the entropy will be,

$$
S=2.4435 \times 10^{-26} \mathrm{erg} / \mathrm{K}
$$

\section{CALCULATION OF SPECIFIC HEAT $\left(\mathrm{C}_{\mathrm{V}}\right)$}

In the same manner, the specific heat $C_{v}$ can be calculated from Eq. (39). For $T=1.7 \times 10^{6} \mathrm{~K}, C_{v}$ is,

$$
C_{v}=2.875 \times 10^{-28} \mathrm{erg} / \mathrm{K}
$$


and for $T=1.7 \times 10^{10} \mathrm{~K}$, it will be,

$$
C_{v}=2.875 \times 10^{-32} \mathrm{erg} / \mathrm{K}
$$

The values of entropy $(S)$ and specific heat $\left(C_{v}\right)$ obtained in Eqs. (51) and (53) respectively, are very small for an incommensurate crystalline structure of the neutron star.

\section{RESULTS AND DISCUSSION}

When the neutron star is formed, the proton - neutron phase is assumed to have a temperature of $T \cong 10^{11} \mathrm{~K}$, and this is called hot phase. Later a stationary hot phase gets established whose temperature $T \cong 10^{9} \mathrm{~K}$. After a few hours of the formation of the neutron star, the final cold stationary phase is established and has a temperature $T \cong 1 \times 10^{7} \mathrm{~K}$. All these temperatures have approximate magnitude $[28,29]$. The change in entropy with time is a consequence of the very process of evolution of the star, and this is due to the attempt of the gravity of the system to sustain the star in a state of quasi - hydrostatic equilibrium. Distant observers on the Earth can only surmise or anticipate or do some approximate calculations about the properties of the neutron star from whatever data they can collect on the Earth. No actual experiments can be done, at least as of to - day, on the surface of the neutron star. Hence the data used and the results obtained in the calculations will be approximate or possible results.

Now the present understanding is that a neutron star has a mass of the order of $1.4 M_{s}$, where $M_{s}$ is the mass of the Sun. This huge mass is contained in a comparatively (when compared to the size of the Sun) smaller radius of the order of $10 \mathrm{~km}$, hence the density of the neutron star is very large and very strong gravitational force exists in the neutron star. The composition of the neutron star with $90 \%$ neutrons and $10 \%$ protons is assumed to be a crystalline state resulting in incommensurate crystallization of the neutron star. Using these parameters, in this manuscript, calculations have been done for the entropy and specific heat of the neutron star. The state of crystallization is immensely rigid under very strong gravitational forces and hence the numerical values of the specific heat and entropy obtained in this paper are very small. Hence, we can write that very small specific heat means that the neutron star in the incommensurate crystalline state does not absorb heat or absorbs very small heat. Similarly, very small entropy means that there will be no disorder (except the zero-point-energy disorder) in the incommensurate crystalline state of the neutron star, and this again, could be due to very large density (more than the nuclear saturation density) and very strong gravitational force. Calculations show that both the specific heat $\left(C_{v}\right)$ and entropy $(S)$, decrease with increase in temperature of the neutron star.

Prevalent models suggest that the crust of the neutron star is extremely hard, but very smooth with maximum surface irregularities of the order of $5 \mathrm{~mm}$, and it is surmised that this is due to very large gravitational field [30].The crust may be composed of very heavy elements like platinum, gold, uranium, iron etc. There $Q$ values can be calculated by the methods outlined in this manuscript. Assuming that the neutron star is composed of these elements, the entropy and the specific heat can also be calculated. We will have to know or assume the comparative abundance of these elements to calculate $S$ and $C_{v}$ [31].

It is not known [31] what exactly is at the centre of the neutron star. Since Pressure is greatest at the centre, it may be composed of hyperons, kaons and pions. The outer $1 \mathrm{~km}$ is assumed to be solid although its temperature is of the order of $10^{6} \mathrm{~K}$ or $10^{7} \mathrm{~K}$. There exists a very strong magnetic field of the order of $10^{12}$ gauss (the Earth's magnetic field is 0.5 gauss). In some cases the magnetic field could be $10^{14}$ and $10^{15}$ gauss. The gravity on a neutron star is roughly 2 billion times stronger than gravity on Earth. It is so strong that it can even bend radiation from the star, and this process is called gravitational lensing. There exist staggering pressures and incompressible density, and this may lead to a neutron superfluid, or an incommensurate crystalline state of the neutron star. It is this state that has been studied in this manuscript [32]. In fact, the entropy of cold crystallized and incommensurate lattice has been studied, and our calculations show that the entropy decreases with increase in temperature of neutron star, and this is in agreement with the second law of Thermodynamics.

In neutron stars, there is decrease of entropy due to gravitational contraction, and this is at the expense of increase in the entropy of the whole environment due to the release of very high - energy radiation (neutrinos) during the life of the stars in the main sequence.

Cumming [33] and his collaborators calculated that the core temperature after the accretion outburst constraints the core specific heat. It was found that the larger the specific heat, the smaller the rise in core temperature during the outburst. Alternatively, if the core temperature is large, the specific heat will be smaller, and this is the result of the calculations done in this manuscript. It may be a good idea to do the calculations by considering the existence of gold, platinum, uranium and silver as part of the lattice. (As a rule the existence of these heavy elements as a part of the incommensurate crystalline structure should lead to reduction of the specific heat $C_{V}$ and entropy $S$ ).

In spite of high temperature of the core $\left(\approx 10^{10} \mathrm{~K}\right)$, due to large gravity stress and very high density in the core of the neutron star, the specific heat $C_{v}$ and the entropy $S$ are very small. This is due to the fact that the core is not able 
to vibrate, and this also means the absence of conventional restlessness in the crystalline state, irrespective of whether we deal with the crystallization of the core or the crust of the neutron star. The study of incommensurate quantum crystal by Anderson [34] for systems on the Earth, $C_{v}=A T^{3}+B T^{7}$, whereas the temperature variation for $C_{v}$ for neutron stars as obtained in this paper is $(1 / T)$.

There is a marked difference between the study of thermodynamics of an incommensurate quantum crystal by Anderson and his collaborators [34] and the study of incommensurate crystallization of neutron matter in neutron stars in this manuscript. In the phenomenological thermodynamic description of low temperature incommensurate quantum solid, Anderson et.al developed a theory in which the lattice constant and density can change independently. In the temperature range considered by them $(\mathrm{T}=0 \mathrm{~K}$ to $\mathrm{T}=1.4 \mathrm{~K})$, the vacancies and interstitials are assumed to be incorporated in a highly correlated quantum state of the system. The temperature dependence is a consequence of the existence of only low frequency modes called phonons. Considering a given mass of helium at a fixed volume, they used the expansion of free energy at low temperature and obtained an expression for the specific heat; $C_{v}=A T^{3}+B T^{7}$. The problem of incommensurate crystallization of neutron matter in neutron stars is quite different. Here the system is composed of $90 \%$ neutrons and $10 \%$ protons. The $90 \%$ neutron sites are considered as vacant sites for protons, and $10 \%$ proton sites are treated as vacant sites for neutrons. Both neutrons and protons are fermions and there are no such thing as low frequency modes of the type of phonons. The density of the helium system is very low, whereas a neutron star has very large density, more than the saturation nuclear density, and hence has extremely high gravitational stress. The core of the neutron star is said to be an isothermal system. The internal structure is extremely compact and strong that it does not permit any disorder. Due to these factors, our calculations lead to very small specific heat and entropy. The variation $(1 / T)$ means that, as $\mathrm{T}$ increases, there is a very small variation in specific heat and entropy in line with the second law of thermodynamics.

The gravity stress, the very high density and the very high temperature at the core of the neutron star result in the lowering of the specific heat and the entropy compared to the values of $C_{v}$ and $S$ at the crust region of the neutron star. Although the core of the neutron star is extremely dense such that the core is not able to vibrate, it still sustains very high temperature, of the order of $10^{9}-10^{12} \mathrm{~K}$. However, the exact structure, density, gravitational stress and temperature of the core of the neutron star is open to discussion. Physicists cannot agree on what exactly happens inside the neutron star.

Once the neutron star is cooled from a temperature of the order of $10 \mathrm{MeV}\left(\cong 10^{10} \mathrm{~K}\right)$ which is the temperature of the neutron star when it is born and cooled by the emission of huge amount of energy via neutrino emission to temperatures of the order of $0.1 \mathrm{MeV}\left(\cong 10^{6}\right.$ to $\left.10^{8} \mathrm{~K}\right)$ or less, it becomes cold and crystalline. Due to very large density, even more than the density of nuclei, there is a huge gravitational stress in the crust to the core of the neutron star. The very large gravitational stress leads to the incommensurate structure of the neutron star. The crystalline structure may be such that, it will not permit any disorder and that means accepting no heat, which means very little entropy and specific heat. This is exactly the result of the calculations done in this manuscript.

Considering a uniform neutron matter inside the crust of the neutron star, calculations showed that the specific heat increases [35]. Whereas for an incommensurate crystalline structure of the neutron star, calculations in this manuscript show that the entropy $S$ and the specific heat $C_{v}$ are quite small.

\section{ORCID IDs}

DKapil M. Khanna, https://orcid.org/0000-0003-4311-9987; DDavid K. Kandie, https://orcid.org/0000-0003-1894-239X

(D) Joel K. Tonui, https://orcid.org/0000-0002-9860-4691; (D) Hezekiah K. Cherop, https://orcid.org/0000-0002-0832-9340

[1] A.F. Andreev and I.M. Lifshitz, JETP, 29, 1107 (1969).

\section{REFERENCES}

[2] U.Z. Dehlinger, Krist. 65, 615 (1927).

[3] J.S. Moreno. Progress in Statistical mechanics Research. (Nova Science Pub. Inc., New York, 2008).

[4] (a) K.M. Khanna, J. Namwitako, T.W. Sakwa, Y.K. Ayodo, A. Sarai, G.O. Barasa and S.J. Prichani, International Journal of Physics and Mathematical Sciences, 5(2), $34-39$ (2015), http://www.cibtech.org/J-PHYSICS-MATHEMATICALSCIENCES/PUBLICATIONS/2015/Vol-5-No-2/03-JPMS-004-SAKWA-THERMODYNAMICS.pdf. (b) A. Lazarides, A. Das and R. Moessner, Phys. Rev. Lett. 112, 150401 (2014), https://doi.org/10.1103/PhysRevLett.112.150401.

[5] NASA, Goddard Space Flight Center, RXTE Guest Observer Facility, https://heasarc.gsfc.nasa.gov/docs/xte/Greatest_Hits/khz.qpo.html.

[6] B.G. Todd-Rutel and J. Piekarewicz, Phys. Rev. Lett. 95(12), 122501 (2005), https://doi.org/10.1103/PhysRevLett.95.122501.

[7] J.S. Namwetako, J.K. Tonui, G.S.W. Murunga and K.M. Khanna, Zero Point Energy as Sea of Energy, Journal of Materials Science \& Nanotechnology, 7(2), (2019).

[8] (a) H. Pawel, A.Y. Potekhin, and D.G. Yakovlev. Neutron Stars 1. Equation of state and structure, Springer science and Business media 326 (2007). (b) F. Özel, D. Psaltis, R. Narayan, A.S. Villareal, On the mass distribution and birth masses of neutron stars, the Astrophysical Journal, 757(1), 55 (2012), https://doi.org/10.1088/0004-637X/757/1/55. (c) J. Timlin, Neutron 
Degeneracy Pressure-Physics, Quantum Mechanics II, Spring (2013); (d) A.W Steiner, J. M. Lattimer and E.F. Brown, The Neutron Star mass radius relation and the Equation of State of dense matter. The astrophysical Journal Letters, 765(1), 5 (2013).

[9] A. Gezerlis, C.J. Pethick and A. Schwenk,Pairing and superfluidity of nucleons in neutron stars (2014), https://arxiv.org/abs/1406.6109v2, (13 April 2015).

[10] (a) S. Jarman, Neutron star marger reveals secrets. Physics world, 31(6), 4 (2018); (b) B. Haskell, N. Anderson, D.I Jones and L. Samuelsson, Are neutron stars with crystalline colour superconducting cores Interesting for the LIGO experiments? (2007), e-print arXiv: 0708.2984v2.

[11] A.G. Vorlesungskriptum, Theoretische physic IV. Statistische physic, (2006).

[12] N.K. Glendenning, Compact stars, (Springer, New York, 1997), pp. 390.

[13] M.I. McMahon and R.J. Nelmes, High pressure Structures and phase transformations in elemental metals, Chem. Soc. Rev. 35, 943-963 (2006), https://doi.org/10.1039/B517777B.

[14] B. Posselt, G.G. Pavlov, Ü. Erta, S. Çalı̧san, K.L. Luhman and C.C. Williams, Discovery of Extended Infrared Emission around the Neutron star RXJ0806. 4-4123, The Astrophysical Journal, 865(1), 1-12 (2018), https://doi.org/10.3847/15384357/aad6df

[15] Superstructure Condensed Incommensurate Solids, in: https://en.wikipedia.org/wiki/Superstructure_(condensed matter).

[16] P. Ehrhart, Properties and interaction of atomic defects in metals and alloys. Chapter 2. New series III, 25, (Springer. Berlin, 1991) pp. 88.

[17] M. Mortazavifar, and M. Oettel, Thermal vacancies in close-packing solids, https://arxiv.org/abs/1311.5093v1. (20 November 2013).

[18] D. Page and S. Reddy, in: https://arxiv.org/abs/1201.5602. (26 January 2012).

[19] P.F. Bedaque, https://arxiv.org/abs/1711.05868.

[20] B. Bertoni, S. Reddy and E. Rrapaj, https://arxiv.org/abs/1409.7750.

[21] C. Vincenzo, Low energy Probes of Physics beyond the Standard Model, https://arxiv.org/abs/1304.0017.

[22] S. Reddy, Thermal and transport properties of neutron star matter, http://www.int.washington.edu/talks/WorkShops/int_16_2b/People/Reddy_S/Reddy.pdf

[23] R. Wijnands, N. Degenaar and D. Page, Cooling of Accretion-heated neutron stars. Journal of Astroophysics and Astronomy, 38 (3) (2017) p.49, https://www.ias.ac.in/article/fulltext/joaa/038/03/0049.

[24] V. Cirigliano, S. Reddy and R. Sharma, Low energy theory for Superfluid and solid Matter and its application to the neutron star crust. Physical Review C, 84(4), 045809 (2011), https://journals.aps.org/prc/issues/84/4.

[25] J.F. Acevedo, J. Bramante, R.K. Leane and N. Raj, Cooking Pasta with Dark Matter: Kinetic and Annihilation Heating of Neuton star Crusts, Nov.14, (2019), https://arxiv.org/abs/1911.06334.

[26] S. Burrello, F. Gulminelli, F. Aymard, M. Colonna, and Ad.R. Raduta, The Heat Capacity of the Neutron Star inner Crust within an extended NSE model. e-print Arxiv: 1511.00304v1, Nov.1, (2015), https://arxiv.org/abs/1511.00304v1.

[27] M. Fortin, F. Grill, J. Margueron, D. Page and N. Sandulescu, Phys. Rev. C, 82(6), 065804 (2010), https://doi.org/10.1103/PhysRevC.82.065804.

[28] F. Barranco, R.A. Broglia, H. Eshenseu and E. Viggezzi, Phys. Rev. C, 58, 1257 (1998), https://doi.org/10.1103/ PhysRevC.58.1257.

[29] A. Pastore, Phys. Rev. 91, 015809, 28 January (2015), in: https://doi.org/10.1103/PhysRevC.91.015809.

[30] J.M. Lattimer and M. Prakash, Astrophys. J. 550, 426 (2001), https://doi.org/10.1086/319702.

[31] S.W.G. Murunga, J. Mater. Sci. Nanotech. 6(3), 303 (2019), http://www.annexpublishers.com/articles/JMSN/6303-Estimationof-the-Abundances-of-Heavy-Elements-Isotopes-in-Neutron-Stars.pdf.

[32] Neutron stars and how they cause Gravitational waves, https://www.nationalgeographic.com/science/space/solarsystem/neutron-stars/.

[33] A. Cumming, E.F. Brown, F.J. Fattoyer, C.J. Horowitz, D. Page and S. Reddy. A lower limit on the Heat capacity of a Neutron star core. Phys. Rev. C, 95(2), 025806 (2017), https://doi.org/10.1103/PhysRevC.95.025806.

[34] P.W. Anderson, W.F. Brinkman and D.A. Huse, Science, 310(5751), 1164-1166 (2005), https://doi.org/10.1126/science.1118625.

[35] G. Lazzari and F.V.de Blasio, Astro. Lett. and Communications. 35, 339-347 (1997), https://ui.adsabs.harvard.edu/\#abs/1997ApL\&C..35..339L/abstract.

\section{НЕРОЗМІРНА КРИСТАЛІЗАЦІЯ НЕЙТРОННОЇ РЕЧОВИНИ У НЕЙТРОННИХ ЗІРКАХ Капіл М. Ханна, Девід К. Канді, Джоел К. Тонуі, Хезекія К. Чероп \\ Фізичний факультет, Університет Елдорет Р.О. Вох 1125-30100, Елдорет, Кенія}

Склад нейтронних зірок від його поверхневої області, зовнішнього ядра, внутрішнього ядра і до його центру все ще досліджується. Можна тільки здогадуватися про властивості нейтронних зірок по спектроскопическим даними, які можуть бути доступні час від часу. У ряді моделей передбачається, що речовина в поверхневій області нейтронної зірки складається 3 атомних ядер, які руйнуються при надзвичайно великому тиску і гравітаційному напрузі, і це призводить до створення твердої решітки з морем електронів, i, можливо, деякої кількості протонів, що протікають через проломи в решітці. Ядра 3 високим масовим числом, такі як залізо, золото, платина, уран, можуть існувати в області поверхні або в області зовнішнього ядра. Встановлено, що структура нейтронної зірки дуже сильно змінюється при переході від поверхні до ядра нейтронної зірки. Поверхня дуже жорстка і дуже гладка. Поверхневі нерівності чи становлять близько 5 мм, тоді як внутрішня частина нейтронної зірки може бути сверхтекучей і складатися 3 виродженого нейтронного речовини. Однак нейтронна зірка є дуже компактні кристалічні системи, і в земних матеріалах, що знаходяться під тиском також було виявлено багато прикладів невідповідних фазових переходів. В результаті були вивчені властивості невідповідною кристалічної нейтронної зірки. Склад нейтронних зірок в сверхплотном стані залишається невизначеним в ядрі нейтронної зірки. Одна модель описує ядро як надплинну нейтронно-вироджену матерію, в основному складається з нейтронів (90\%) i 
невеликої відсотка протонів і електронів (10\%). Можливі більш екзотичні форми матерії, включаючи вироджену дивну матерію. Це також може бути невідповідна кристалічна нейтронна матерія, яка може бути ВСС або НСР. Використовуючи принципи квантової статистичної механіки, була розрахована питома теплоємність і ентропія невідповідною кристалічної нейтронної зірки виходячи 3 припущення, що температура зірки може змінюватися від до Були довільно обрані два значення для температури Т $-1.7 \times 10^{6} \mathrm{~K}$ i $1.7 \times 10^{10} \mathrm{~K}$ для яких були зроблені обчислення. Значення питомої теплоємності $\mathrm{i}$ ентропії зменшуються з ростом температури, а також їх величини дуже малі. Це відповідає другому закону термодинаміки. КЛЮЧОВІ СЛОВА: земні матеріали, нерозмірна фаза, нерозмірна кристалічна нейтронна зірка, надтекучість, вироджена нейтронна матерія.

\section{НЕСОРАЗМЕРНАЯ КРИСТАЛЛИЗАЦИЯ НЕЙТРОННОГО ВЕЩЕСТВА В НЕЙТРОННЫХ ЗВЕЗДАХ Капил М. Ханна, Дэвид К. Канди, Джоэл К. Тонуи, Хезекия К. Чероп \\ Физический факультет, Университет Элдорет Р.О. Вох 1125-30100, Элдорет, Кения}

Состав нейтронных звезд от его поверхностной области, внешнего ядра, внутреннего ядра и к его центру все еще исследуется. Можно только догадываться о свойствах нейтронных звезд по спектроскопическим данным, которые могут быть доступны время от времени. В ряде моделей предполагается, что вещество в поверхностной области нейтронной звезды состоит из атомных ядер, которые разрушаются при чрезвычайно большом давлении и гравитационном напряжении, и это приводит к созданию твердой решетки с морем электронов, и, возможно, некоторого количества протонов, протекающих через бреши в решетке. Ядра с высоким массовым числом, такие как железо, золото, платина, уран, могут существовать в области поверхности или в области внешнего ядра. Установлено, что структура нейтронной звезды очень сильно меняется при переходе от поверхности к ядру нейтронной звезды. Поверхность очень жесткая и очень гладкая. Поверхностные неровности едва ли составляют порядка 5 мм, тогда как внутренняя часть нейтронной звезды может быть сверхтекучей и состоять из вырожденного нейтронного вещества. Однако нейтронная звезда представляет собой очень компактные кристаллические системы, и в земных материалах, находящихся под давлением также было обнаружено много примеров несоразмерных фазовых переходов. В результате были изучены свойства несоразмерной кристаллической нейтронной звезды. Состав нейтронных звезд в сверхплотном состоянии остается неопределенным в ядре нейтронной звезды. Одна модель описывает ядро как сверхтекучую нейтронно-вырожденную материю, в основном состоящую из нейтронов $(90 \%)$ и небольшого процента протонов и электронов $(10 \%)$. Возможны более экзотические формы материи, включая вырожденную странную материю. Это также может быть несоразмерная кристаллическая нейтронная материя, которая может быть ВСС или НСР. Используя принципы квантовой статистической механики, была рассчитана удельная теплоемкость и энтропия несоразмерной кристаллической нейтронной звезды исходя из предположения, что температура звезды может изменяться от $10^{6} \mathrm{~K}$ до $10^{12} \mathrm{~K}$. Были произвольно выбраны два значения для температуры $\mathrm{T}-1.7 \times 10^{6} \mathrm{~K}$ и $1.7 \times 10^{10} \mathrm{~K}$ для которых были сделаны вычисления. Значения удельной теплоемкости и энтропии уменьшаются с ростом температуры, а также их величины очень малы. Это соответствует второму закону термодинамики.

КЛЮЧЕВЫЕ СЛОВА: земные материалы, несоразмерная фаза, несоразмерная кристаллическая нейтронная звезда, сверхтекучесть, вырожденная нейтронная материя. 